\title{
Research on Closed-Loop Teaching Mode Based on SPOC Platform-Taking the PAD Model for Course of Financial Analysis as an Example
}

\author{
Wenshuang Bao ${ }^{1, *}$ and Shuyan Zhang ${ }^{1}$ \\ ${ }^{1}$ School of Accounting, Shandong Management University, Jinan, Shandong, 250015, China \\ *Corresponding author.Email: bws@sdmu.edu.cn
}

\begin{abstract}
With the increasing abundance of online resources, MOOC, SPOC and other teaching platforms are gradually being widely used in the educational field. The integrated teaching mode of theory and practice, which is limited to knowledge and classroom teaching, also exposes the problems in reviewing knowledge, one-sided case information and analyzing practical aspect. Taking the financial analysis course as an example, this paper combines SPOC platform with PAD class to study the integration programs. This paper first puts forward three main problems in teaching, that are students with weak foundations, with one-sided case description and lack of in-depth case studies. And then it designs a cyclic classroom model to support a closed-loop teaching method, which involves the completion of theoretical research and case study on the platform before the next class and the discussion of the subjects in the form of a task list about the financial position and performance in the previous cases.
\end{abstract}

Keywords: SPOC, PAD, Teaching of Theory and Practice, Financial Analysis

\section{INTRODUCTION}

Under the background of the popularization and informatization of higher education, the requirements from society for application-oriented institutes are constantly improving. As the "new coordinate" of China's current higher education reform, the cultivation to qualities and abilities promotes the development of the "integration of theory and practice" classroom through PAD teaching mode[1]. With the establishment of many MOOC courses by Stanford University and other famous international universities since 2012, the mode of "MOOC" has attracted the attention of the global educational field, which allows more learners to enjoy the happiness of knowledge acquisition from this highly inclusive, inter-communication and fragmented online learning mode[2]. However, there are some shortages in the practice of MOOC, such as the decreasing efficiency of teaching and learning due to the increasing class sizes that result in a lack of communication between learners and lecturers. For this reason, SPOC mode emerges in response to the proper time and conditions[3]. As a Small Private Online Course, SPOC is more conducive to the combination of online and offline blended teaching mode. With SPOC platform as the carrier, the learners could online-learn by themselves. This content includes reading materials, watching videos, submitting assignments and online tests, etc., which can effectively complement and extend for teaching in a classroom. This is an updated PAD model-presentation, assimilation, discussion[4-5].

\section{PROBLEMS IN THE COURSE TEACHING OF FINANCIAL ANALYSIS}

As a compulsory course for financial management major and an optional course for other business management majors, Financial Analysis requires the coordination of theoretical explanation, case analysis and practical analysis in the teaching process. In the current teaching process of application-oriented universities, there are mainly the following problems.

\subsection{The foundation of students is weak}

Financial Analysis is based on financial statements, which requires students to be familiar with the content, format, main items and the relationship among financial statements and be able to use them flexibly. This is why the course is generally arranged in the junior year. Classes are given after students have completed intermediate financial accounting and intermediate financial management, so that students can integrate knowledge points and comprehensively apply them in the process of financial analysis. However, in the actual teaching, it is found that for students the mastery of financial knowledge is limited on accounts, accounting recording and other accounting work practices. Especially they lacked the overall conceptual framework of financial statements, which exposes that each item of 
the report cognition is relatively independent and lack connection[6].

\subsection{The case is one-sided}

The process of financial analysis requires not only financial information but also contact with the environment of the enterprise, analysis of the internal control of enterprises. In this situation, case teaching is a very effective way, therefore, in the teaching process, most teachers have involved rich case to analyse. However, neither in textbooks nor in databases, cases are almost independent. What's more, only part of the enterprise information is explained for the specific analysis skill and then guided to case analysis. In advantages, even if one aspect of the analytical ability of students is insufficient, it will not affect the performance of the other part of the skills development; while in reality, the financial analysis for an enterprise is inseparable from the whole, all information and each part. The simple analysis of a certain index cannot state what the financial position of the enterprise is, or the performance is strong or weak. Moreover, the development prospect of an enterprise cannot be judged through some independent index. Only by comprehensive judgment of all analysis conclusions, the relatively comprehensive and useful decision information could be obtained. On the other hand, the cases are mainly descriptive by economic phenomena, and they are presented in the big language of "numbers" and "finance". This will lead to a lack of "daily" and "can be discovered" language environments which the learners need to practice in. This also tends to make students doubt the authenticity of the cases, so it is difficult to arouse students' interest. As a result, learners' ability of collecting and dealing with information cannot be improved.

\subsection{The analysis is superficial}

For application-oriented universities, the course is affected by the total standard credits and class hours of the major, so that the length of the course in classroom, such as Financial Analysis, is gradually shrinking. Therefore, to ensure the integrity of the knowledge system, teachers need to cut a lot content including review of the knowledge and presentation of the analysis process. Taking the Shandong management university as an example, the course of Financial Analysis is a total of 48 classes hours right now. The teachers need to explain the financial information, the analysis theory, the foundation of analysis methods, analysis program, and presenting the analysis process for each skill. Besides, it is necessary to set aside time for the students to do practice and present, in order to evaluate the ability of analysis skills for each learners. In this series of processes, students and teachers would have no enough time in exploring the potential information and doing in-depth research on the profitability and solvency of enterprises.

\section{PAD TEACHING DESIGN BASED ON SPOC}

For the courses with much content and practice in limited hours, PAD teaching mode based on SPOC platform can effectively implement the integrated teaching method of theory and practice. As a result of reviewing fundamental theory online by themselves before class-teaching, the teachers could link knowledge points, present the analysis process, answer questions, discuss, evaluated to practice and so on in class. In this way, it not only cultivates the ability of independently learning and time managing, but also makes use of limited classroom time in effective communication, which would greatly increase students' learning enthusiasm[7]. This paper takes the course of Financial Analysis as an example and designs the teaching mode with the SPOC platform and PAD teaching mode as follows.

\subsection{Front-end analysis: target design, platform selection}

The course Financial Analysis in the Accounting School of Shandong Management University is the core professional course in Undergraduate Program for major of Financial Management, with 3 hours per week, 16 teaching weeks per semester, so that 48 hours in total. The course is offered in the second semester of the junior year. At that time, students have completed the course of Intermediate Financial Accounting and Intermediate Financial Management, so that the students meet the requirements of the course to enter the SPOC platform. By learning Financial Analysis, students can master the means of obtaining information for financial analysis, grasp the theoretical knowledge of analysis procedures, and be able to choose appropriate methods for analysis to conduct in-depth analysis of financial statements, and finally provide the objective analysis conclusions in order to help managers make an economic decision. Since teaching mode on SPOC is derived from reversing the order of theoretical knowledge teaching in class and discussion after class, and changing the thinking of traditional classroom learning, it would make the best use of students' fragmented time to complete the simple understanding and theory self-test, and focus on the core literacy of deep learning as a key step to improve the ability[8].

We select the SPOC resource of Financial Analysis from the platform of Higher Learning Online Open Coursed. The online and offline courses have the same main textbook and the teaching schedule is generally consistent. Except for the teaching video for the textbook, the platform resources can also provide students with pre-class guidance, self-test after class and interactive discussion materials, which matches the degree of classroom teaching. 


\subsection{Design of teaching activities: preview before class, self-study after class and study in class}

Considering the course schedule, that is there are different hours in the first and second week; this paper proposes double weeks as a teaching cycle, which means six hours in three classes is a cycle. Meanwhile, the course content is divided into eight elements, with six hours for each. The contents of each module are interrelated to form a complete analysis case. In the first class of each cycle, knowledge is taught under the framework as guiding students to think deeply. By sorting out the key points and difficult points and structuring the knowledge system, students are guided to establish learning goals, and required to complete the self-study task lists on the platform. Before the second class, the self-learning content includes watching the course video online, discussing the chapter questions and self-testing online. Teachers will publish research questions for class-teaching according to the results of discussion and self-test. In the second class of each cycle, it is for group discussion and inter-group communication according to the task list, and then the teachers will answer questions and summarize finally. Before the third class, students are required to submit the abstract of group discussion report. Teachers will select one or two groups according to the briefing and invite them to share the opinion in the next class. The third class of each cycle is for group presentation and summary. The teacher should give an evaluation of each student personally after the class. The design of teaching activities is shown in the following Fig. 1.

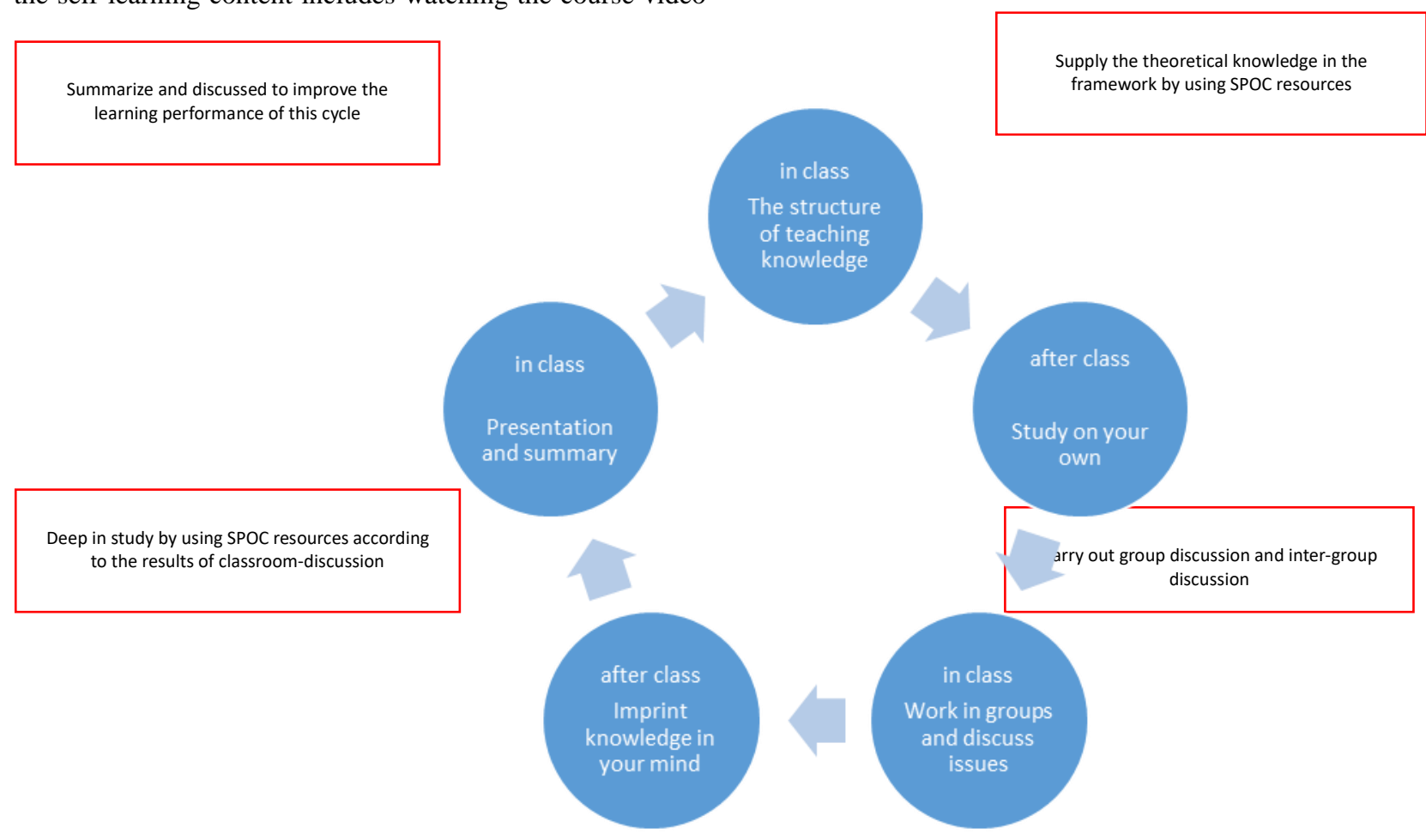

Figure 1. Activity design

\subsection{Evaluation design: self-study task lists, study the task lists in class}

The evaluation system of performance in PAD with SPOC, includes online evaluation and process evaluation in class. Online evaluation includes completion of video schedule, the participation of chapter discussion, and the results of online self-test. While the offline evaluation includes continuous personalized evaluation according to completion of task in face-to-face class and the result of the final report submitted within a specified time. The multi-dimensional process assessments can satisfy the comprehensive evaluation of learners' in-depth learning results and effectively guide the cultivation of students' application ability.

\section{CONCLUSION}

Teaching reform is a long-term systematic project, and the influence of science and technology in the field of education is far less than that of other fields. With the development of the Internet in teaching, online learning is not merely on the surface. By improving on the teaching mode, the flexibility of learning and the depth of the analysis according to PAD based on SPOC is in rapid development. In view of the traditional theory with analysis skills classes, it should build a teaching mode 
that can improve students' ability of analysis by using the SPOC platform. So it is stated in this paper:

\subsection{Based on SPOC platform, carrying out the closed-loop teaching reform of PAD model}

The teaching content of practice in enterprise management and financial analysis cannot only stay in the scene described by textbook resources, but it should also reflect the financial result by combining with the changing political, economic and legal environment. The richness and high-speed updating of SPOC platform resources meet the environmental requirements of analysis and provide key factors for analysis practices. Combined with the PAD classroom model, it can effectively promote students' absorption and utilization of knowledge and improve their ability of dialectical thinking.

\subsection{Transfer and supplement of theoretical knowledge by SPOC platform}

In the PAD model, teachers release multi-level teaching resources and tasks through SPOC platform, and students complete corresponding tasks according to their theoretical knowledge to achieve the goal of differentiated teaching. By unlocking the hierarchical task, students are made sure to meet the basic conditions of knowledge and obtain the completed analysis information before the corresponding PAD class, so as to prepare for the improvement of classroom participation.

\subsection{Making use of the rich resource library of the SPOC platform to analyze on a complete case}

During the teaching process, teachers can update the financial data of the case and the economic environment in time by means of network links, sharing videos, etc., so that the teaching cases have credibility and practical significance. Students can also pay attention to the case enterprises through the Internet and other channels, which, on the one hand, improves the ability of knowledge transfer and the ability to deeply explore the meaningful information, and on the other hand, ensures the validity of the analysis results.

\subsection{Taking tasks as the guide, conduct in-depth study and case study}

Analysis and discussion in the sub-classroom can't stop at only one result, but need to be deep step by step. With three sessions as a cycle; teachers can effectively go deep into the process of improving students' analysis skills, which can meet the high-level teaching requirements of practical financial analysis.

\section{ACKNOWLEDGMENT}

SDMU Project, Research on PAD classroom Teaching with SPOC Platform-Taking the course of Financial Analysis as a case, ZJG2019-13.

\section{REFERENCES}

[1] Xuexin Zhang, “On divided classroom: a new exploration of classroom teaching reform in Universities," Fudan Education Forum, vol. 12(5), pp. 5-10, 2014. (In Chinese)

[2] Qiuzhen Ouyang, MAO Linglin, Li Xiaoqin, "Econometrics uses 'SPOC platform +PAD model' to carry out research on 'three-dimensional integration' teaching reform in the context of transformation," Modernization of education, vol. 62, pp. 71-73, 2019. (In Chinese)

[3] Xiaochun Wang, "Research on the PAD teaching mode of university course based on SPOC," Heilongjiang Higher Education Research, vol. 281, pp. 173-176, 2017. (In Chinese)

[4] Song Gao, Yu Xiu, Juan Sun, "Discussion on the application of SPOC platform in the teaching of Traditional Chinese Medicine," Education and Teaching Forum, vol. 19, pp. 272-274, 2020. (In Chinese)

[5] Yanchun Liu, "Knowledge interaction research of MOOC+SPOC new blended teaching mode," Harbin Institute of Technology, 2018. (In Chinese)

[6] Raluca Sava, "Using interactive methods in teaching accounting," Studies in Business and Economics, vol. 2016-2.

[7] Qi Dang, "Study on SPOC online learning behavior and its influencing factors," Hangzhou Normal University, 2019. (In Chinese)

[8] Ping Wang, "Research on the design and application of teaching mode on SPOC with the perspective of deep learning," Yan'an University, 2020. (In Chinese) 